\title{
SORPTION CAPACITY OF A HYDROGEL BASED ON POLYHEXAMETHYLENEGUANIDINE HYDROCHLORIDE
}

\author{
OLEG S. OCHIROV ${ }^{1 *}$, DANIIL N. OLENNIKOV ${ }^{2}$, MARIA N. GRIGOREVA ${ }^{1}$, SERGEY A. \\ STELMAKH ${ }^{1}$, DMITRY M. MOGNONOV ${ }^{1}$ \\ ${ }^{I}$ Baikal Institute of Nature Management, Siberian Division, Russian Academy of Science, 6, Sakhyanova Street, Ulan-Ude \\ 670043, Russian Federation \\ ${ }^{2}$ Institute of General and Experimental Biology, Siberian Division, Russian Academy of Science, 6, Sakhyanova Street, Ulan- \\ Ude 670043, Russian Federation
}

*corresponding author: Ochirov.o.s@yandex.ru

Manuscript received: November 2018

\begin{abstract}
The study was performed in order to assess the sorption capacity of a hydrogel based on polyhexamethyleneguanidine hydrochloride by using the method of doping the hydrogel with cefotaxime antibiotic from the cephalosporin series. According to the HPLC method with UV detection the sorption of antibiotic into the hydrogel was more than $50 \%$ and the percentage of drug released within 40 minutes exposure to ultrasound was $15 \%$. The study results showed the possibility of using hydrogels based on polyhexamethyleneguanidine hydrochloride as potential drug carrier.
\end{abstract}

\section{Rezumat}

Studiul a fost efectuat pentru a evalua capacitatea de sorbție a unui hidrogel pe bază de clorhidrat de polihexametilenguanidină, utilizând metoda dopării hidrogelului cu cefotaxim, antibiotic din seria cefalosporinelor. Conform metodei HPLC cu detecție UV, sorbția antibioticului în hidrogel a fost mai mare de $50 \%$, iar procentul de medicament eliberat în timpul expunerii la ultrasunete timp de 40 de minute a fost de $15 \%$. Rezultatele studiului au arătat posibilitatea utilizării hidrogelurilor pe bază de clorhidrat de polihexametilenguanidină ca potențial drug-carrier.

Keywords: hydrogel, cefotaxime, sorption, polyhexamethyleneguanidine

\section{Introduction}

Various ointments based on substances of plant or animal origin are widely used to treat damaged skin [1]. Over the past few decades, the synthesis of new polymer materials has led to the production of highly effective drugs for wound healing [2-4]. These polymer compounds are mainly used in drug delivery and they do not have biological activity. One of the urgent tasks of modern polymer chemistry and medicine is to discover universal drug delivery systems that would be able to provide antimicrobial effect and also act as a drug carrier. The interest in water-swellable polymers has increased due to the emergence and development of a new direction in polymer chemistry - the creation of stimulus-sensitive polymeric materials that can respond to external influences in a predetermined way [5]. The use of such materials in systems of controlled release $[6,7]$, encourages researchers to develop and optimize the properties of already known polymers. Nowadays, polymeric hydrogels are widely used. Hydrogels are spatial-cross-linked macromolecules of polymers that could be used as drug carriers.

Among gel-forming polymers are guanidine polymers, in particular, polyhexamethyleneguanidine hydrochloride (PHMGH) known for its high antimicrobial activity [8]. Previously, we have obtained the hydrogel based on PHMGH [9] that has pronounced wound healing properties and a similar effect with analogous products. The paper presents new data regarding the sorption capacity of the hydrogel based on PHMGH, using the method of doping the formulation with cefotaxime, antibiotic from the cephalosporine series.

\section{Materials and Methods}

\section{Infrared spectroscopy}

IR spectra were taken on ALPHA device (Bruker, Germany), ATR attachment (ZnSe crystal), 4000 $600 \mathrm{~cm}^{-1}$.

Microcolumn HPLC with UV detection

Microcolumn liquid chromatograph Milichrom A02 (EcoNova, Novosibirsk, Russia) coupled with column ProntoSIL-120-5-C18 AQ $(2 \times 75$ mm, $\Phi 5$ $\mu \mathrm{m}$; Metrohm AG, Herisau, Switzerland) were used for the quantitative determination of Cefotaxime. Eluent A was $0.2 \mathrm{M}$ lithium perchlorate $\left(\mathrm{LiClO}_{4}\right)$ in $0.006 \mathrm{M}$ perchloric acid $\left(\mathrm{HClO}_{4}\right)$ and eluent $\mathrm{B}$ was acetonitrile. Gradient elution (0 - 26 min 5 - 100\% B, 26 - $29 \min 100 \% \mathrm{~B}$ ) was performed at eluent rate $150 \mu \mathrm{L} / \mathrm{min}$, column temperature $35^{\circ} \mathrm{C}$, and $\mathrm{UV}$ detector wavelength $330 \mathrm{~nm}$. The calibration curves 
for cefotaxime quantification were created by plotting the peak areas vs. the concentration ranges $1-1000$ $\mu \mathrm{g} / \mathrm{mL}$ using reference sample of cefotaxime (Krasfarma JSC, Russian Federation; batch No 180216). All the analyses were carried out in triplicate and the data were expressed as means \pm standard deviation (SD). Gel samples $(20 \mathrm{mg}$ ) previously milled through $\leq 0.125 \mathrm{~mm}$ particles were transferred to Eppendorf tubes $(2 \mathrm{~mL})$. After adding $1 \mathrm{~mL}$ of water the mixture was subjected to ultrasonic processing $(50 \mathrm{kHz}, 10 \mathrm{~min}$, $\left.40^{\circ} \mathrm{C}\right)$. Then the mixture was centrifuged $(6000 \mathrm{~g}$,
$20 \mathrm{~min})$ and filtered through the membrane filter $(0.45 \mu \mathrm{m})$. The supernatant $(1 \mu \mathrm{L})$ was used for the HPLC-UV quantification.

\section{Results and Discussion}

The formation of a spatially cross-linked structure of the hydrogel PHMGH hydrochloride is possible in two ways: crosslinking as a result of prolonged polycondensation [10] and crosslinking the terminal amino groups of PHMGH with formaldehyde (Figure 1).

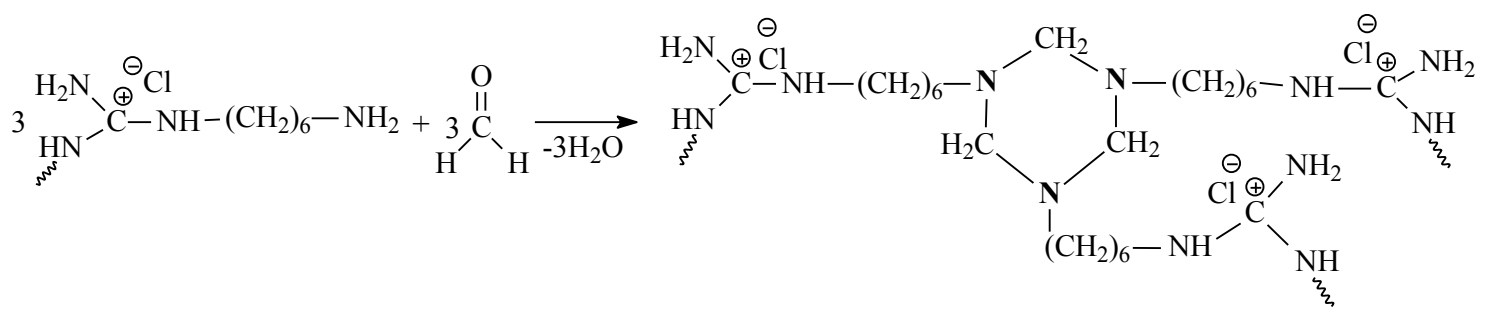

Figure 1.

Formation of a PHMGH hydrogel

The proposed structure of the hydrogel was confirmed by the methods of IR spectroscopy and elemental analysis (Table I) of model compounds synthesized by the interaction of hexamethylenediamine (one of the precursors of PGMGH) and formaldehyde (Figure 2).

Table I

Elemental analysis data of the model compound

\begin{tabular}{|l|c|c|c|c|}
\hline & \multicolumn{4}{|c|}{ Calculated/found } \\
\hline Elements & $\mathrm{C}, \%$ & $\mathrm{H}, \%$ & $\mathrm{~N}, \%$ & $\mathrm{O}, \%$ \\
\hline $\begin{array}{l}\text { Model } \\
\text { compound }\end{array}$ & $69.56 / 68.44$ & $10.14 / 11.28$ & $20.20 / 19.95$ & - \\
\hline
\end{tabular}

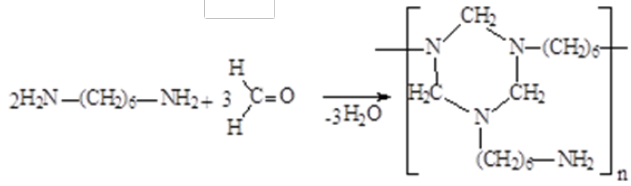

Figure 2.

The interaction between formaldehyde and hexamethylenediamine
The IR spectrum of the model compound shows (Figure 3) that in the amino absorption region of $3200 \mathrm{~cm}^{-1}$ and $1600 \mathrm{~cm}^{-1}$, there is no characteristic absorption of amines and carbonyl groups at $1700 \mathrm{~cm}^{-1}$, which indicates the complete conversion of the initial monomers. In the region of $2780 \mathrm{~cm}^{-1}$, the observed signals can be attributed to the absorption of an isolated methylene group between nitrogen atoms. To confirm this assumption, polyvinyl formal from polyvinyl alcohol was synthesized according to a standard procedure [11], in the structure of which there is a similar isolated methylene group between oxygen atoms. Comparing the IR spectra of polyvinyl formal and the model compounds, it was found that in the $2780 \mathrm{~cm}^{-1}$ region there are similar oscillations that are absent in polyvinyl alcohol and characterize the valent symmetric vibrations of the isolated $-\mathrm{CH}_{2}$ group [12].

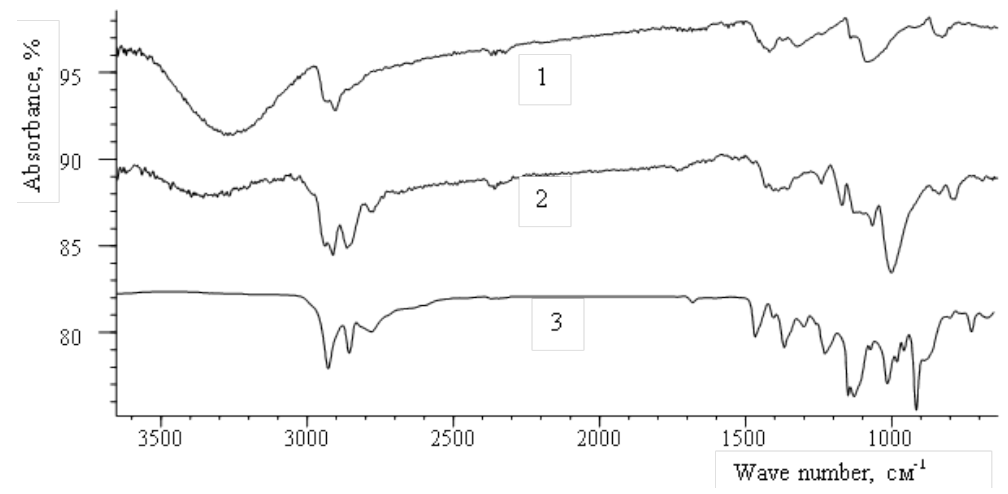

Figure 3.

IR spectra of polyvinyl alcohol (1), polyvinyl formal (2), model compound (3) 
On the IR spectrum of the hydrogel, there is no signal in the region of $2780 \mathrm{~cm}^{-1}$, probably due to the smaller number of such groups. So, when comparing the spectra of PHMGH and hydrogel (Figure 4), it can be seen that in the absorption region of amino groups at $3250 \mathrm{~cm}^{-1}$, the hydrogel shows a decrease in the band intensity, which is explained by the consumption of terminal amino groups of the polymer that interact with formaldehyde. Due to the formation of a methylene bridge connecting the terminal amino groups, nitrogen atoms exhibiting a negative inductive effect, increase the polarity of the $-\mathrm{CH}_{2}$ - group, blocking scissors deformation vibrations $\left(1460 \mathrm{~cm}^{-1}\right)$, while provoking the fan and torsion amplification in the range of $1350 \mathrm{~cm}^{-1}$ up to $1270 \mathrm{~cm}^{-1}$.

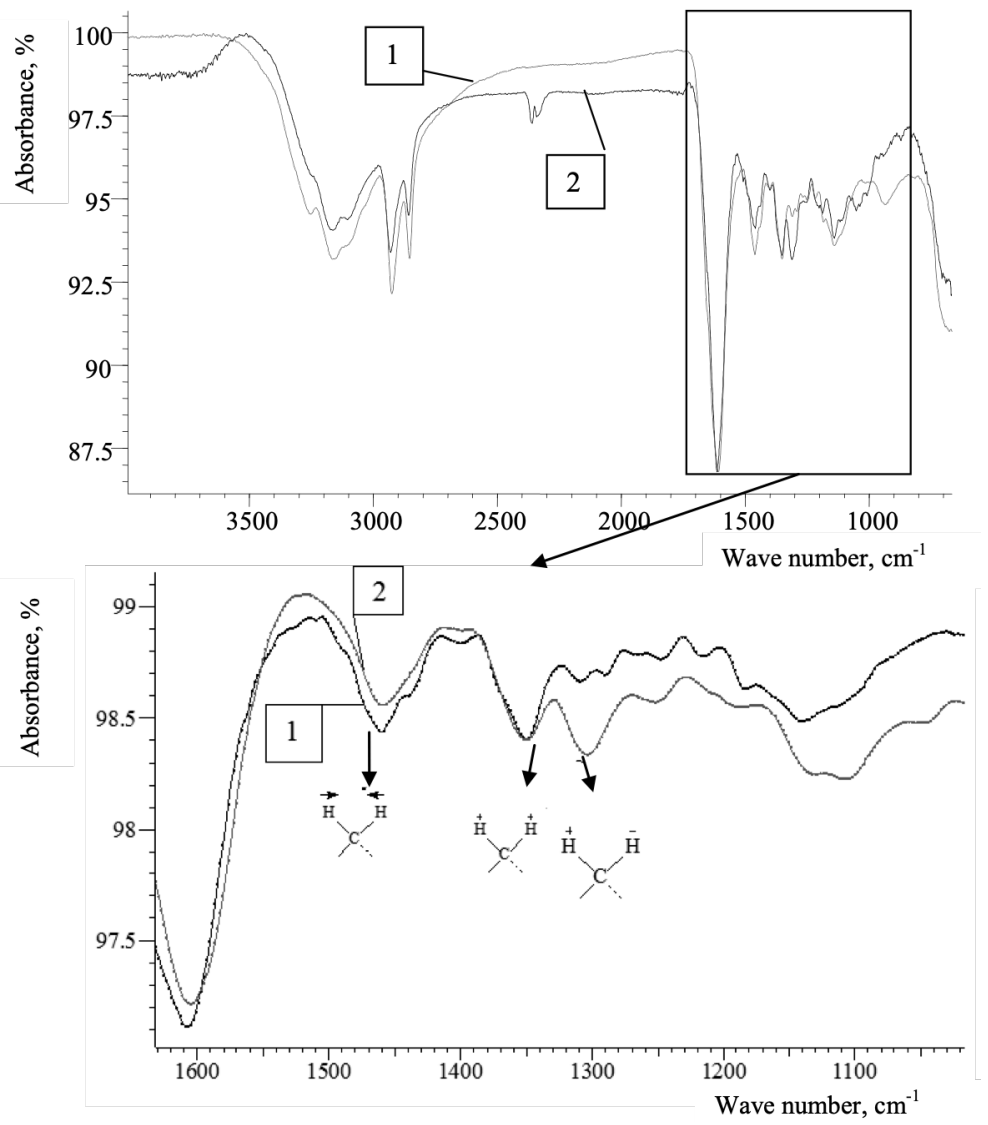

Figure 4.

IR-spectra. PHMGH (1), hydrogel (2)

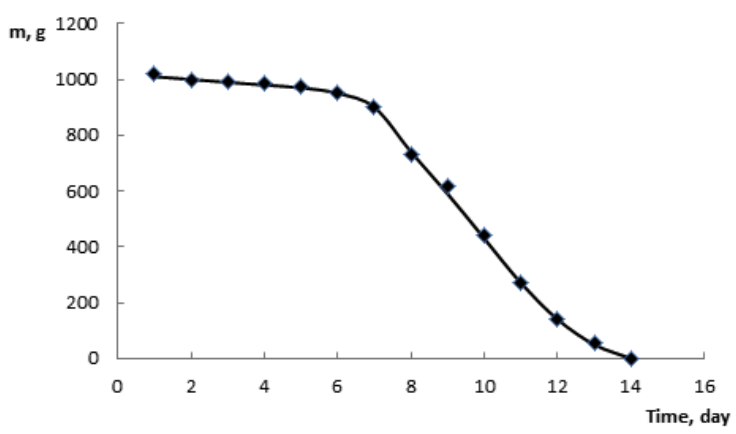

Figure 5.

Dynamics of mass change of the hydrogel within 14 days

The hydrogels obtained by crosslinking with formaldehyde have antimicrobial activity and pronounced wound-healing effects [13]. It is important to point out that the hydrogels of this type were subjected to

degradation within 14 days, so the storing should be in a dry form (Figure 5).

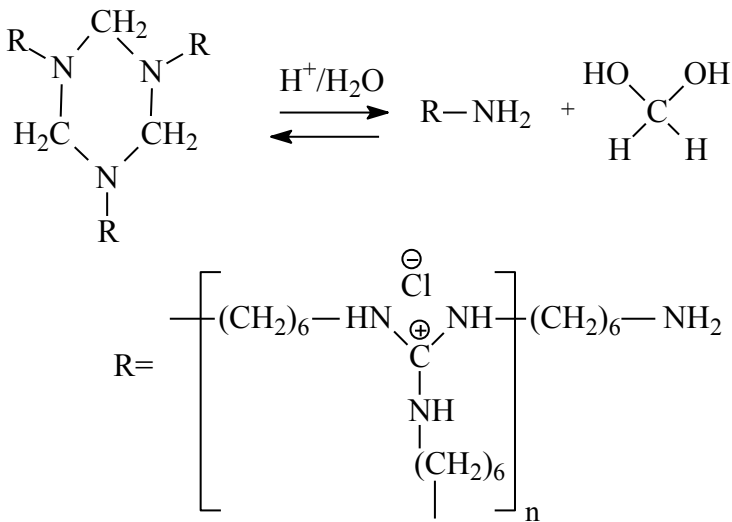

Figure 6.

The formation of the hem-diol 
In fact, the process of disintegration leads to the release of the initial polymer, the presence of which was confirmed by the IR spectroscopy. Figure 7 shows the spectra of the hydrogel and decay product comparable with each other.

The method of UV spectroscopy failed to detect the formaldehyde released during the decomposition of the hydrogel. The most likely explanation for this fact is the formation of the hem-diol (Figure 6). In the future, a detailed study of the process of destruction of the hydrogel is planned, using other methods of physical and chemical analysis.

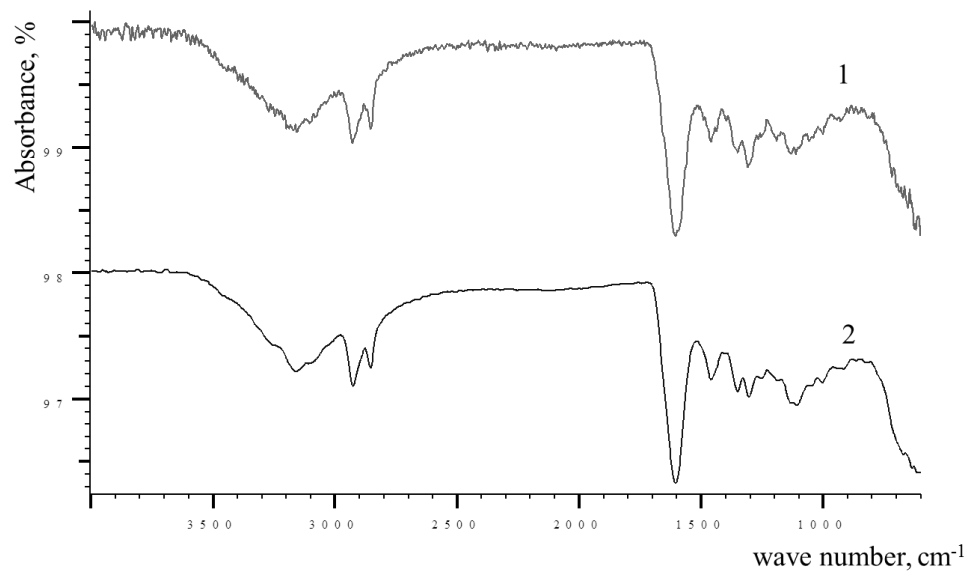

Figure 7.

IR Spectra. Hydrogel (1); hydrolysis product (2)

The disintegration of the hydrogel can be used for drug development. So a new drug composition was obtained while studying the sorption of the hydrogel. Cefotaxime, antibiotic from the cephalosparin series, was used as a sorbed substance. The choice of this drug was caused by it accessibility for wound healing in general practice.

The solution of antibiotic in distilled water with a loaded charge of the dry hydrogel was used. The retention time of the hydrogel until complete swelling

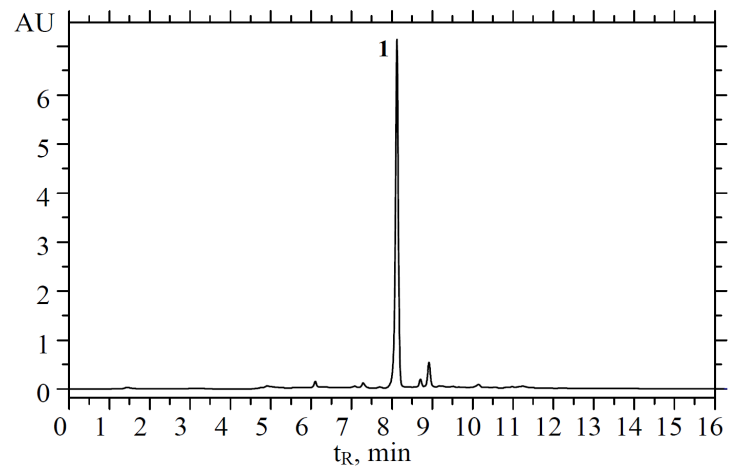

Figure 8.

Cefotaxime (1) solution after adsorption by the hydrogel $(5.6 \mathrm{mg} / \mathrm{mL})$

Our data showed that the hydrogel can be used as a drug carrier. Prolongation of the drug effects will be provided through partial degradation of the hydrogel with a constant-rate release of the drug from the hydrogel. was $30 \mathrm{~min}$. As a result, a part of antibiotic was absorbed by the hydrogel from the solution according to the results of HPLC analysis (Figure 8).

Figure 9 shows the antibiotic concentration is 5.6 $\mathrm{mg} / \mathrm{mL}$ from the reference content $(12.20 \mathrm{mg} / \mathrm{mL})$. This indicates more than $50 \%$ of sorption. The composition of the hydrogel with antibiotic after 40 min extraction released about $1.5 \%(15.8 \mathrm{mg} / \mathrm{g})$ from the active substance (Figure 7).

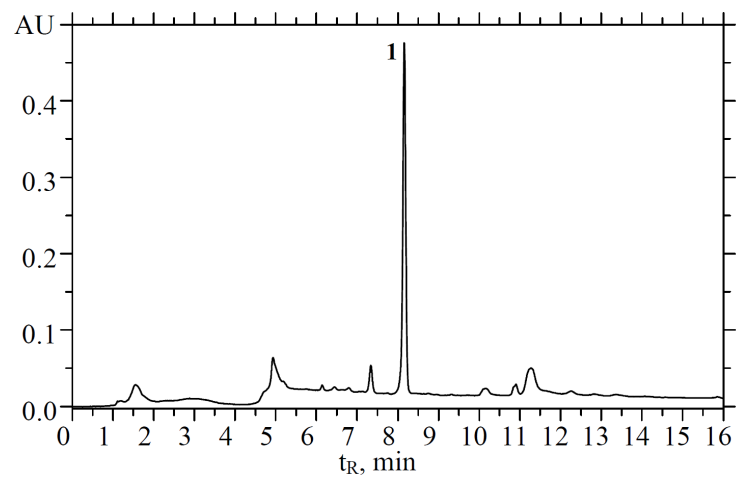

Figure 9.

Cefotaxime (1) released from hydrogel $(10.2 \mathrm{mg} / \mathrm{mL})$

\section{Conclusions}

The structure of the polyhexamethylene guanidine hydrochloride hydrogel was confirmed by IR spectroscopy and elemental analysis. It has been established that a swollen hydrogel is prone to degradation with a probable mechanism of hydrolysis 
leading to the release of the initial polymer and formaldehyde in the form of hem-diol. Further studies will be conducted on the mechanism of the hydrogel hydrolysis, since our analysis were limited due to the lack of standards.

The study of the sorption activity of the hydrogel using the example of the antibiotic cefotaxime showed that the hydrogel can act as a matrix of a carrier of drugs, for pharmaceuticals used in the treatment of damaged skin. Further studies will be made to develop new compositions with plant-based substances with wound healing properties.

\section{Acknowledgement}

The study was performed in the framework of the state assignment of Baikal Institute of Nature Management of RAS and with the financial support of RFBR (Russian Foundation for Basic Research) grant No. 18-315-00233.

\section{References}

1. Budovsky A, Yarmolinsky L, Ben-Shabat S, Effect of medicinal plants on wound healing. Wound Rep Regener., 2015; 23(2): 171-183.

2. Ahmed EM, Hydrogel: Preparation, characterization, and applications. $J$ Adv Res., 2015; 6(2): 105-121.

3. Zhu SW, Li SR, Escuin-Ordinas H, Dimatteo R, Xi WX, Ribas A, Segura T, Accelerated wound healing by injectable star poly(ethylene glycol)-b-poly (propylene sulfide) scaffolds loaded with poorly water-soluble drugs. J Controlled Rel., 2018; 282: 156-165.

4. Noori S, Kokabi M, Hassan ZM, Poly(vinyl alcohol)/ chitosan/honey/clay responsive nanocomposite hydrogel wound dressing. J App Polym Sci., 2018; 135 (21): 1-12.
5. Pavlyuchenko VN, Ivanchev SS, Primachenko ON, Khaikin SYa, Danilichev VF, Proshina VS, Trunov VA, Lebedev VT, Kul'velis YuV, Polymer hydrogels for immobilization of medicinal substances with memory effect. Polym Sci Series A, 2011; 53(4): 560-573.

6. Eeckman F, Moes AJ, Amighi K, Evaluation of a new controlled-drug delivery concept based on the use of thermoresponsive polymers. Int $J$ Pharm., 2002; 241: 113-125.

7. Galaev IYu, Mattiasson B, Thermoreactive watersoluble polymers, nonionic surfactants, and hydrogels as reagents in biotechnology. Enz Microb Tech., 1993; 15: 354-366.

8. Ochirov OS, Stel'makh SA, Mognonov DM, Hydrogels based on polyalkiylguanidines and aldehydes. Polym Sci Series B, 2016; 58(3): 334-340.

9. Grigor'eva MN, Stel'makh SA, Astakhova SA, Tsenter IM, Bazaron, LU, Batoev VB, Mognonov DM, Synthesis of polyalkylguanidine hydrochloride copolymers and their antibacterial activity against conditionally pathogenic microorganisms Bacillus cereus and Escherichia coli. Pharm Chem J., 2015; 49(2): 99-103.

10. Grigor'eva MN, Stel'makh SA, Bazaron LU, Mognonov DM, pH-Sensitive hydrogels based on polyhexamethyleneguanidine hydrochloride. Rus J App Chem., 2011; 84(4): 724-726.

11. Ushakov SN, Polyvinyl alcohol and its derivatives. Published 1960; Publisher USSR Academy of Sciences Moscow, USSR.

12. Nakanishi K, Infrared Absorption Spectroscopy, Practical. Published: 1962; Publisher: Holden-Day Inc, San Francisco, USA.

13. Lebedeva SN, Ochirov OS, Stelmakh SA, Grigor'eva MN, Zhamsaranova SD, Mognonov DM, Reparative action of hydrogel polygexamethylenuanidine hydrochloride. Byulleten Sibirskoy Meditsiny, 2018; 17(1): 112-120. 